\title{
"It's Just a Never-Ending Battle": The Role of Modern Hygiene Ideals and the Dynamics of Everyday Life in Constructing Indoor Ecologies
}

\author{
Rachael Wakefield-Rann' \\ Institute for Sustainable Futures, University of Technology Sydney, \\ Australia \\ Dena Fam \\ Institute for Sustainable Futures, University of Technology Sydney, \\ Australia
}

Susan Stewart

Faculty of Design, Architecture and Building, University of Technology Sydney, Australia

\section{Abstract}

Recent research suggests that the greatest threat to children's health from home environments across much of the industrialized world may no longer be pathogenic microbes, but impoverished microbial communities and the chemicals used in everyday products, including those for cleaning. This paper proposes that concepts of hygiene should be updated, given this reorientation of harm. However, little research has been conducted, which a) integrates knowledge from the diverse disciplinary fields concerned with indoor environments (such as microbiology, chemistry, and design), and b) examines how individuals conceptualize and enact hygiene to create healthier indoor environments for their families, including the extent to which their practices achieve this.

To gain insight into factors influencing how hygiene is enacted in the home, as well as the consequent effects on the composition of indoor environments, it is necessary to transgress traditional disciplinary approaches to investigate indoor environmental health and integrate knowledge from experts and lay people who inhabit these spaces. To do this, recent scientific and design literature addressing key determinants of environmental health in homes are consulted. This is combined with qualitative research into the ways in which parents define, perform, and measure hygiene

1 Corresponding author: rachael.wakefield-rann@uts.edu.au. 
within domestic spaces. The data collected concerns homes in Sydney, Australia, with the findings showing that common hygiene practices with potentially harmful outcomes often emerge from compromises between competing priorities within complexes of home practices. Factors influencing the dynamics that determine which activities are prioritized and how they are performed are dually highlighted. Some notable factors include confusion and uncertainty associated with the sensory proxies used to determine cleanliness and risk of harm, increased sensitivity to the potential presence of microbes over other potentially harmful microspecies, and the health histories and experiences of parents and children.

Keywords: cleaning practices, home microbiome, hygiene, indoor ecology, social practice theory

\section{Introduction}

Human ecology is concerned with the coevolution of complex cultural-economictechnological systems and physical-chemical-living systems, and the effects of their often-unpredictable emergent properties on the health of humans and ecosystems (Dyball \& Newell, 2014). Much of the current literature in the field of human ecology is focused on macroscale interactions between human societies and regional or global environmental conditions, while dedicating relatively less attention to microscale (or indoor) ecosystems. ${ }^{2}$ As such, this paper proposes that the microecology of the indoors warrants greater attention, particularly as it is now considered not only the fastest growing biome on Earth, but also an increasingly significant source of human and environmental health hazards (Martin et al., 2015). Air pollution in the home is now ranked the ninth largest Global Burden of Disease risk (Forouzanfar et al., 2015). Those most susceptible to its effects, including the very young and elderly, and those with compromised health, are likely to have higher exposure than those who spend less time indoors (Kumar et al., 2016). The types of health hazards present in home environments are complex, varied, and geographically contingent (Lyytimäki, 2012). In much of the developing world, key sources of indoor pollution include smoke from fires and cigarettes, while in developed countries pollutants primarily emanate from consumer products (Kumar et al., 2016). Products commonly used in home cleaning and bathing practices also contain classes of chemicals, such as phthalates and some solvents, identified as harmful to human and environmental health (Clayton et al., 2011; Gosens et al., 2014). Of the approximately 80,000 chemicals registered for use in consumer products, only a small percentage have been tested for their long-term effects (National Toxicology Program, 2018). However, recent research has demonstrated that many of those used in common personal care and cleaning products have carcinogenic or endocrine disrupting effects (Bergman

2 A notable exception here is Lyytimäki (2012). 
et al., 2013; Weschler, 2009; Zoeller et al., 2012), which are particularly harmful to children. Endocrine disrupting chemicals (EDCs) have in the past been linked to health conditions including diabetes, obesity, some cancers, and impaired reproductive and neurological development (Bergman et al., 2013).

In addition to chemical pollutants, a crucial determinant of indoor environmental health is the microbial communities that thrive therein. Homes can become sites in which pathogenic bacteria and viruses are transferred between people, and fungus can develop in damp areas, which may cause allergic reactions. However, a lack of microbial diversity in homes, and the absence of farm or domesticated animals that carry particular microbes to "train" human immune systems, have been associated with the rise in childhood allergies (Rook et al., 2013) and leukemia (Greaves, 2018). The design of domestic objects, homes, and the use of antibacterial products have all been associated with declining microbial diversity in homes (Dunn et al., 2013; Flores et al., 2013; Rintala et al., 2008). For example, the use of chemically treated finishing such as antimicrobial paint, chemical cleaning products, and home designs that restrict airflow between the indoors and outdoors can all contribute to a decrease in microbial diversity, potentially encouraging more resistant microbial species to thrive and colonize (Adams et al., 2016; Martin et al., 2015; Meadow et al., 2014).

Despite clear evidence from chemistry and microbiology fields that practices central to modern lifestyles influence indoor environmental health, there remains a gap in the literature examining how different material, biological, and cultural forces come together to create particular "microecologies" in one's home. Moreover, no evidence could be found of research that examines how modern ways of defining and maintaining a hygienic home affects the composition of domestic microecologies, which, in turn, influence health outcomes.

This paper begins to address this gap by moving beyond discipline-specific investigations to integrate perspectives on indoor environmental health. It examines how home hygiene is enacted in practice, and how these practices might contribute to suboptimal indoor home environments. The transdisciplinary approach that broadly guided this research is defined here through four criteria: problem oriented, participatory or collaborative, transgressing disciplinary boundaries, and seeking to integrate disparate fields of knowledge (Brown et al., 2010; Schoot Uiterkamp \& Vlek, 2007; Wickson et al., 2006). Based on this orientation, the following section details how and why an approach focused on social practices was adopted to trace relations between social and material elements within home environments, which may influence the composition of domestic microecologies. 


\section{Research Approach: Tracing Home Hygiene Practices}

Although heterogeneous, theories of social practice generally focus on the dynamic interplay between material things, meanings and beliefs, and embodied knowledge at different scales of social life (Hui et al., 2016; Shove, 2004). A commonly cited definition of practice provided by Reckwitz (2002) describes a practice as:

a routinized type of behaviour which consists of several elements, interconnected to one another: forms of bodily activities, forms of mental activities, "things" and their use, a background knowledge in the form of understanding, know-how, states of emotion and motivational knowledge. (p. 249)

Research that foregrounds the importance of practices allows insights that integrate the latent and explicit influences of hygiene in the design of domestic interiors and objects, the deliberate and the unquestioned ways of performing particular activities (e.g., dishwashing and toothbrushing), and the more deliberate cognitive decisions and beliefs about what constitutes a healthy environment. All routine activities conducted in one's home, such as cooking, watching television, and getting ready for work, determine the flows of materials in, out, and around such buildings. However, some practices, such as cleaning, have a more direct role in structuring a home's microecology, due primarily to the common use of products containing antimicrobials and other EDCs, and the frequency and ubiquity with which they are used (Halden et al., 2017; Sherriff et al., 2005). Some scholars (see Maller, 2018; Wakefield-Rann et al., 2018) have argued that common conceptualizations of materiality in theories of social practice do not sufficiently account for nuances in material agency. They consequently propose that elements of other more-thanhuman theories are integrated into investigations of practice to explore material agency in greater depth. Nonetheless, this paper contends that practice theories provide a compelling lead framework to enable a necessary investigation and articulation of the ways in which the dynamics of everyday practice structure the composition of indoor environments.

\section{Conceptualizing and Practicing Hygiene}

The ways that cleaning practices are conducted are closely linked to how hygiene is understood and measured. Hygiene is defined as the "conditions or practices conducive to maintaining health and preventing disease, especially through cleanliness" (Oxford English Dictionary, 2016). However, since the mass popularization of germ theory, hygiene has increasingly become synonymous with sterility, thus, narrowing its focus on the extermination of "germs" (Campkin \& Cox, 2012; Pink \& Mackley, 2015; Shove, 2003; Smith, 2007). Moreover, Shove (2003) and others (see Campkin \& Cox, 2012; Smith, 2007) have argued that cleanliness 
conventions have escalated and become standardized across the industrialized world in late modernity. These escalating and increasingly complex standards of hygiene, and the market's capitalization of such trends, have meant that the networks of products mobilized in daily cleaning practices command ever-higher levels of energy, materials, and chemicals to produce the desired functionality (Shove, 2003).

This paper adopts the term "microspecies" to help broaden its investigation of home hygiene to account for the complex interactions between microbes and other significant microentities, which influence health and disease outcomes (WakefieldRann et al., 2018). "Microspecies" include microbes (i.e., bacteria, archaea, protists, fungi, and other microscopic animals and plants), and active organic and inorganic chemicals that exist at a microscale (i.e., invisible to the human eye) in homes. For the purposes of this research, the separation of living microbes from non-living chemicals obscures important shared traits related to how they act, react, and influence the environments in which they exist. Unlike visible species, microspecies can only make their presence known through proxies that must be read by humans, such as odor, discoloration of surfaces and clothes, skin rashes, and illness. The complex interactions between microspecies, guided by the actions and objects that populate daily life, shape a home's "microecology," and determine if it constitutes a hygienic and healthy environment for human habitation.

\section{Research Sample and Recruitment}

This research draws on data collected from a qualitative study conducted in Sydney, Australia, with 10 parents of children under five during 2017. A key aim was to investigate the ways in which competition between complexes of practices structure the enactment of hygiene in domesticity. This necessitated significant depth of engagement with each participant, and the adoption of multiple research methods. The exploration of complex phenomena in this research benefited from a sample size of 10 (Creswell, 1998; Malterud et al., 2016; Morse, 1994).

Respondents were primarily female $(9 / 10 ; 90 \%)$, which may reflect availability and degree of engagement with domestic environmental health issues, as suggested by other research (Mackendrick, 2014). The characteristics of the final participant sample affords insights into the complexes of practices performed by women from English-speaking backgrounds, who work full or part time, and are of a middle to high socioeconomic status. Although the latter component was not deliberately selected for in the sample, insights into the domestic practices of this group can be considered valuable given the expansion of a "middle class" in Australia and globally. Additionally, the normative lifestyle practices of such social groups may form the basis of aspirational changes made by upwardly mobile families (Koo, 2016). 
Given the limitations of the study, a multitude of potential variables that could contribute to the constitution of home microecologies were not investigated. In particular, further research that examines differences in rural and urban practices, cultural practices, house size and composition, and geographic location would add further nuance to studies concerning how hygiene is defined and prioritized, and how it is expressed when the dynamics of practice shift under different influences.

Methods used included a "cleaning diary," semi-structured interviews, and practice reenactments in participants' homes. The cleaning diary required participants to record all domestic cleaning or hygiene-related activities conducted over a period of seven days. This method, adapted from Sofoulis's (2005) water diaries, highlighted the associations and motivations that shaped key forms of engagement between participants, products, other objects, and perceived sources of environmental risk or "uncleanliness" that transpire throughout a day or week. Although there are clear limitations to self-reporting methods, the diaries provide a valuable indication of the frequency of particular activities, how cleaning and hygiene are defined by participants, and how cleaning is entwined with other practices. After completing these diaries, participants were invited to partake in a semi-structured interview with practice reenactments in their homes, in which they demonstrated their use of particular products and the ways they approached cleaning different parts of their house.

A combination of the cleaning diary, interviews, and practice reenactments allowed participants' practices to be accessed from different angles, rather than relying exclusively on narrative descriptions of different activities. The diaries provided a sense of the temporal dimensions of practice, while the situated interviews and reenactments enabled participants to demonstrate how they engage with particular materials and why. By situating interviews in participants' homes, there were opportunities to be reminded of certain activities, product choices, irritations, quirks, and other features of their homes that guide how they clean while physically moving through space.

Interview data were professionally transcribed and thematically analyzed with NVivo qualitative data analyses software. The thematic codes centered on the focal areas listed above, and how competition within and between practices and practitioners influence how, when, and by whom the home is cleaned, as well as how different activities are prioritized. What follows is an examination of the findings from this research, and how the interactions between practices that structure the flow of daily life shape how and when cleaning is performed, and its implications for home microecologies. 


\section{Hygiene Outcomes and Competition Within Complexes of Practices}

The interviews and reenactments situated in participants' homes revealed that all had owned products that contained chemicals known or suspected to contribute to suboptimal indoor environments and health conditions; the most common sources of which were antimicrobial and fragrance chemicals. However, the types, ways, and degrees of product use were determined by numerous factors attributable to competition between rival interests within bundles and complexes of practices. Key factors influencing these dynamics include how hygiene priorities shift after having children, the way time and resources are allocated to different practices under time pressure, how these dynamics influence the delegation and performance of tasks, and the implications for the composition of domestic microecology.

Within social practice literature, coexistent practices are often described in terms of "bundles" of practices, which are loosely intertwined through colocation and coexistence, such as watching television and eating dinner (Shove et al., 2012). Conversely, "complexes" of practice are more integrated and interdependent arrangements, which concern such acts as handwashing and eating. A focus on the dynamics of complexes and bundles of practices, rather than exclusively examining meanings or attitudes toward home hygiene, has generated insights into how competing priorities, such as family time, leisure time, work, the aesthetic of one's home, and geographic and infrastructural elements, influence how hygiene is enacted.

The majority of parents interviewed reported that time pressures had a significant influence on how they prioritized tasks related to cleaning. For eight of the 10 participants who were engaged in paid employment, the arrival of children simultaneously reduced the amount of time available for maintaining such spaces, while introducing a range of new hygiene concerns.

After having children, greater emphasis was placed on removing potential germs from floors and benches, while activities such as tidying became less of a concern. Participant 6 stated:

there's probably lots I do now that I never would have been so fussed about. Just in terms of keeping, probably, surfaces way more clean, way more often. Probably, yeah, frequency is the biggest—would be the biggest thing, for sure. Then, yeah, probably floors. Just in terms of using Dettol and stuff. I would have never have thought-I just would have used a floor cleaner rather than an antibacterial thing like that. 
This heightened concern over the germs children might encounter (particularly on surfaces) meant the cleaning methods sought were less time and labor intensive, but effectively addressed perceived hygiene risks. As a result, antibacterial surface sprays and wipes were reported as popular options by all participants. These products enable the effective removal of food, toilet mishaps, or any kind of grime without having to clean an entire surface or area. This is illustrated well by Participant 3: "I've got these Dettol antiseptic wipes that I use to wipe the floor and her [participant's daughter] surface because I actually put the food straight on there, so she's feeding off that surface."

The preference for children to dwell in clean environments, coupled with the undesirability of prioritizing cleaning over other pursuits, such as family time or work, means that parents often delegate a certain amount of cleaning to professional services and objects. Although all parents interviewed conducted some amount of cleaning, six of the 10 employed a professional cleaner: one weekly, one fortnightly, three monthly, and one as needed. A common reason provided was that the perceived time required to clean one's home adequately would detract too much from the time they spend with family. Children also create more constant and new types of mess compared to adults, thus, seeing parents more often engage in frequent "spot cleaning," and, consequently, delegating the less urgent and more substantive tasks to professionals:

The stuff we've let go since we had [child], because we just don't have the time, is vacuuming, which we basically now have a cleaner that comes every four weeks and does it. We don't really do dusting. We don't clean in the inside of the oven. We don't clean the bathtub or the walls of the shower space. We let the cleaner do all that ... The stuff that we do, continue to do, is the vital kitchen-related [jobs] ... cleaning dishes ... wiping surfaces, kitchen table, high chair. (Participant 5)

Tasks performed by cleaners are often more time and product intensive than those parents reported to conduct on day-to-day bases. An implication of outsourcing more substantial cleaning tasks is that parents are often unaware of what products are being used to clean their homes. Only one of the six participants who hired a professional cleaner specified the products they wanted used, while the others indicated they were unaware of such details:

Do you know what? ... they come while I'm at work, so I'm not even here. I actually have no idea what they [cleaners] use or what they do ... so I'll come home from work on the day the cleaners have been ... Before I give the boys a bath that night, I actually wash out the whole bath with water, because I can feel that it's got-you know how you can feel it's got residue on it? ... I'm like, oh God, I don't want him soaking in something, I don't know what it is. (Participant 9) 
Many of the materials and interactions influencing domestic microecologies are not the result of decisions directly made by parents about a particular microspecies of concern. Rather, the emergent cleaning practices include products selected according to attributes desired by cleaners who are required to achieve a cost-effective, yet satisfactory appearance of cleanliness for their client. Of all the parents who used professional cleaners, only one directed their cleaner to use "more natural products" (Participant 2). For the majority of participants, the delegation of cleaning reduced their awareness of the types of microspecies introduced to their homes through cleaning practices. Consequently, a result of delegation is often a greater reliance on chemical agents, rather than on cleaning practices that involve a significant investment of time and effort.

Time pressure resulting from competition between practices also influences how and where parents shop for products to maintain home hygiene. When asked what factors guide product choices, convenience was a significant aspect. When asked why certain products were selected, Participant 1 noted, "whatever's convenient at the time. So if we're over at [shopping center] doing shopping, that will be where we purchase things." Even when parents are concerned about particular product attributes, purchasing decisions were not always made on that basis. Rather, competition between practices within a given timeframe would be resolved by adopting the most convenient bundling of activities, even when that meant compromise on product choice.

Hygiene outcomes emerge from specific resolutions of competing practices, not only in the context of individual decision-making, but also between members of a household. The specific ways of cleaning, how it is valued and prioritized by different individuals, and the combinations of personal care and cleaning products used in different rooms by different people all influence the composition of a home's microecology. In some cases, one person was responsible for the majority of housework and shopping; however, in most cases, these tasks were shared to varying degrees. Consequently, divergent hygiene, aesthetic, and time-related priorities were at play. As Participant 6 explained:

[my partner] and I have a continual disagreement about personal care products ... He likes things that really foam up, like a good body [lather], and I'm just like, that's all not really good for you ... but he wants [sports brand] stuff with beads in it or whatever.

When asked about the use of antibacterial personal care products, Participant 6 also stated:

that's another thing that [partner] and I disagree about ... He's pro, and I'm anti ... Because I just don't feel like it's a necessary step, and I feel like it's quite hard on your skin, especially for kids. I would rather that they just washed their hands. 
These examples demonstrate that the flow of microspecies through one's home from different products is guided by a confluence of interests and the tensions between them. Hence, the way practices are prioritized echoes back to transform the meanings used to justify and make sense of how they end up being performed. This effect was particularly apparent in relation to the exposure of children to "dirt" or "grime." In eight cases, after expressing concern about not having time to clean their house to a suitable standard, participants stated that some exposure to dirt was acceptable, or even beneficial. For example, Participant 9 indicated she felt less guilty about her existing practices when she learned that some exposure to germs was valuable:

I think-actually two things. Maybe just time-wise, I just didn't have time to get on top of him, to get him clean and hands washed. Secondly, I watched a [documentary] on-it was about allergies, but it was about kids that are exposed to different types of bacteria really early on in their life are less likely to have an allergy later on in life ... So, then I think I was more conscious of, well, maybe that—yeah, not—everything doesn't have to be so clean ... Well, it gave justification for me not being very tidy. I don't know. I was like, see, I'm doing something good for him.

Despite the persistence of germ-centric narratives and practices of hygiene risk in the home, the necessity of relinquishing some control over dirt-child interactions recounted by Participant 9 did seem to facilitate a partial erosion of the belief that such interactions are necessarily harmful, even where instinctive commitment to the belief remained. Similarly, residual discomfort with how competing practices had been prioritized was expressed in parents' attempts to limit the direct exposure of their children to chemicals. Participants expressed a desire to avoid products (such as surface sprays) containing chemicals, particularly on children's skin, despite continuing to use them other surfaces with which children interact in other ways. For example, Participant 6 stated:

yeah, I just think ... as natural as you can get it as possible, because I think that there's a real issue with plastics and chemicals ... particularly with little boys; in boys it can influence reproductive systems. So, I've tried to reduce the amount of ingredients—chemical ingredients- that go on their skin.

The inconsistency of chemical avoidance around children can be understood as a manifestation of competing practice demands. Antibacterial chemical sprays and wipes generally offer the most convenient options for dealing with the perpetual mess generated by young children, particularly if one is already busy. These products are also imbued with sensory attributes designed to reassure users they are effectively cleaning, such as scent (e.g., lemon and pine), and lather and shine, all of which are achieved through the addition of chemicals (Wakefield-Rann, 2017).

A number of social theorists have noted the different ways that changing relations between practices have been recognized as influencing the temporal rhythms of daily life (see Blue, 2017; Hui et al., 2016; Schor, 1998; Southerton, 2006). As they 
argue, the perceived decrease in available time does not result from any single factor, but instead from the "squeeze of practice-related injunctions of sequencing, coordination and personalized scheduling" (Shove et al., 2012, p. 95). As Southerton (2006) noted, each practice is accompanied by a set of requirements that enables competent and meaningful engagement to be achieved. These requirements must be balanced with those of other practices, so that the sets of practices carried, and their respective demands in terms of duration and timing, determine the overall sense of time pressure (Southerton, 2006, p. 440).

Overall, this section has argued the manner in which hygiene is performed in participants' homes emerges from a negotiation between competing practices and priorities experienced by each individual, and between those who share such responsibility. Participants demonstrated the need to accommodate and synchronize numerous practices that require significant time commitments, such as work, food preparation, taking care of children, shopping, and cleaning. The need to negotiate the requirements of each practice resulted in a mediation of the materials, meanings, and bodily competencies that often give priority to faster, labor-saving methods, such as the use of surface sprays and wipes to conduct reactive cleaning when needed, rather than time-consuming, routinized, and systematic cleaning of whole areas or rooms. As such, this paper next presents findings relating to the crucial elements and perceived practice requirements that influence the ordering of practices, which affect how hygiene is defined and maintained in the home.

\section{Sensory Proxies Biased Toward Microbes}

The elements forming a practice determine the amount of time, energy, thought, and skill required for its performance. These relative demands influence how practices subsequently interact with other practices, including how they are prioritized. The preceding section detailed how parents often feel they do not have time to clean their homes to a standard they deem acceptable, resulting in the delegation of particular tasks to others and the use of products perceived to be more effective and efficient at eliminating microbes. However, this section presents findings that suggest the way hygiene and "cleaning well" have been defined in practice instead necessitate a degree of engagement and rigor not achievable without significant time and labor commitments. Participant 9 captured this notion:

I just found that ... even with one kid, never mind two ... everything was always filthy. I think it's the adjustment to having a child in the house and being tired.

So I got a cleaner once a fortnight, and we've kept it since. 
This section draws on the data to examine the standards and sensory proxies that have come to represent hygiene and "cleaning well," and the implications these have for how and when cleaning is performed. In particular, it highlights a significant oversensitivity embedded within cleaning practices to the potential risks posed by microbes.

The sensory qualities of microspecies play a significant role in how their capacity to cause harm is assessed. A unique characteristic of microspecies (compared to macrospecies, such as humans and pets) is their lack of detectability, which sees individuals instead rely on sensory proxies, such as scents or visual clues, to determine their presence. However, these are not always reliable indicators of microspecies' presence, or of the type of threat they may pose. If a house constantly presents signals of germs - such as discolored white tiles, dirty marks on flooring, or lingering bathroom odor-the time and energy that parents perceive they must dedicate to cleaning becomes considerable, influencing how tasks are performed and prioritized in dynamic daily negotiations between practices.

In all cases, the study research indicated that participants were more sensitive to sensory proxies for microbes than chemicals. This finding supports existing research that suggests the minds and senses, particularly of people in Western industrialized cultures, have been trained to perceive microbes through multiple sensory inputs, including foul odor, sticky surfaces, or visible dirt or discoloration (Smith, 2007), while other microspecies lack the proxies that enable their detection. This exemplifies what Murphy (2006) termed a "regime of perceptibility," in which the skills required to perceive harmful chemicals have not been as culturally or physically entrained as those required to perceive "germs." This "regime" was expressed not only through narratives, but also in product designs that make certain forms of dirt more detectable, and in the ways bodies are trained to recognize and react to the presence of particular materials and substances.

The design of one's home, interior furnishings, and building materials all influence how participants determined how and when certain areas required cleaning. All participants were particularly sensitized to the presence of visible dirt on flooring, and its implications for their children's health. The non-porous, light-reflecting qualities of floorboards reassured participants that dirt would not be "hidden" as it would in carpet. The following quote from Participants 8 illustrates how floorboards reveal dirt in particular ways that other surfaces, such as carpet, may obscure:

Because it's all floorboards in this house ... I get up in the morning and the sun comes beaming through this window here and it will show every single cat hair ... I always think, I thought that floor was clean. It's actually just covered in cat fur [laughs]. So that's when I think, okay, I've got to clean the floors today. So even though without the sun shining on, it's actually—it looks okay, it's really not. It really just needs cleaning. 
The revelation of "dirt" on surfaces influences the flow and prioritization of practices by commanding immediate attention. The ways in which dirt and other substances materialize on surfaces also guides product choices. For example, three participants noted their aversion to soap because of the "scum" it creates on shower tiles and glass. The aesthetic qualities of surfaces were also identified as key deterrents for parents attempting to use less chemical-intensive products for cleaning, such as vinegar and bicarbonate soda. The expected "sparkle" and "shine" of surfaces, which are thought to represent cleanliness, are often not achievable without such harsh intervention. As Participant 1 noted, "I have tried some other things and I've tried some natural methods. I've tried vinegar and water and ... That didn't quite do it. It didn't get that sparkle."

These examples corroborate historical accounts of domestic objects demonstrating how the design of cleaning appliances has not only been guided by the increased demand for convenience and efficiency, but also by an imperative to make pathogencarrying dirt more visible (Smith, 2007). In their history on the aesthetics of modern homes, Lupton and Miller (1996) described the process by which hygiene became the driving aesthetic in bathroom design from 1890s England, where white porcelain fixtures made from vitreous china and enameled iron were liberated from their moisture and germ-gathering dark wooden enclosures, and made flush with both floors and walls, thus, rendering dust and grime immediately visible. Similarly, when vacuum cleaners became standard household appliances in postwar periods within Europe, the United States, and Australia, dirt on flooring was able to be aggregated and made visible in the dust-collector of such machinery, hence, providing persuasive evidence of the necessity and virtue of the task and its performance (Lupton \& Miller, 1996).

The intertwining of hygiene, design, and aesthetics throughout the twentieth century complicates the meanings, materials, and skills that constitute cleaning practices. Although microbes are made more perceptible by many modern furnishings and objects, cleaning may be further motivated by a desire to maintain surface aesthetic than by the perceived need to remove microbes. However, due to the legacy of hygiene in twentieth- and twenty-first-century design, definitions of a presentable and attractive home are inextricably bound to a "clean" aesthetic of uninterrupted, simple surfaces, which require active and ongoing maintenance.

This section has argued that the evolution of cleaning practices, alongside definitions of hygiene that require dirt to be revealed and removed, has resulted in aesthetic norms that demand significant time and labor investments. Parents' inability to meet these perceived norms, given that other practices demand their attention, has made faster and more efficient cleaning options more attractive. A key way that greater efficiency is achieved is through targeted applications of chemical-intensive products, such as antibacterial sprays and wipes. As such, focus now turns to the 
instances in which parents have become sensitized to non-microbial environmental risks in the home, and how this has influenced the performance and negotiation of domestic cleaning practices.

\section{Health History Sensitizes Parents to New Microspecies}

Despite the relative dominance of microbes over other microspecies (such as chemicals) in the perceptual landscape of one's home, disruptive factors were identified that increased the sensitivity of parents to chemicals in particular circumstances. The reactivity of children's skin, especially due to eczema, was the most pronounced factor that sensitized parents to new microspecies affecting children's health. Rashes that appear as a result of eczema and other allergies are disruptive events that introduce new variables to consider within cleaning practices, often causing confusion and uncertainty. Such disruptions to normal cleaning practices made many parents begin to read the labels on cleaning and personal care products for the first time. The two most notable disruptions were reactions in children's bodies, particularly on skin, and the health experiences of mothers. These two types of incidence enabled the perceptual dominance of microbes to partially recede, and chemicals and other allergens to become more apparent. In relation to learning about chemicals in products, Participant 2 noted:

I'd never thought about it before ... then I think it all started because my son had eczema and I think then the first thing was to consider what washing powder you're using because it can be irritating to the skin. Then that was what started the whole journey into reading more about these types of things.

The other significant factor that sensitized parents to new microspecies was the health experiences of mothers. For example, Participant 2 had undergone a long process of diagnosing "ongoing low energy and digestive problems." A lack of solutions led her to newly examine the ingredients of products, and prompted her to start removing certain chemicals from her family's diet and home practices. Participant 2's increased awareness of chemicals in products resulted in a heightened sensitivity and an aversion to the proxies for chemicals, such as strong product scents:

With the laundry powder, I can't stand the strong commercial [products]—like, I can smell when the neighbors are doing their washing. I just can't-I hate that smell. Like, a friend just gave me some pants that didn't fit her and I just can't stand the smell of them because I've quite a strong sense of smell, I think, and I can't stand the really strong-like, I like things that have the natural, pleasant smell, not if it's really super strong. 
Other participants' health experiences influenced their sensitivity to chemicals in other, more conditional ways, which resulted in a practice change for a limited period of time. For example, Participant 1 explained how she became more aware of the chemicals in products, and began to avoid them when she commenced in vitro fertilization (IVF):

I mean, the reason why I was sort of a little bit more conscious of it is because I had to do IVF with both the boys. So I guess I was trying to sort of think, okay, I'm not going to jeopardize anything ... So I think at the time I made sure that I wasn't using any nail polishes unless they were chemical free ... I avoided any sort of hair products and even getting my hair dyed, and things like that for a while.

The participant acknowledged the potential for particular chemicals to cause harm by adjusting her practices, and had limited her use of certain personal care products by avoiding her hairdresser; however, most of these practices were abandoned after the children were born. When asked if these chemicals and products were only ceased during pregnancy, Participant 1 stated, "yeah, yeah probably ... Also, going back to work and things like that."

Participant 1's experience meant her practices were altered for a duration in which she believed particular products might cause her body harm. However, the demands of other practices, such as working and looking after two children, meant she reverted back to using products in practices that enabled her to achieve a state of personal and home hygiene efficiently, which satisfied her usual high standard. In contrast, the chronic nature of Participant 2's health condition resulted in a permanent alteration to her practices to avoid harsh chemicals.

This section has highlighted that participants often dissociate "vulnerability" from mainstream practices and chemical use, except when alerted to the susceptibility of particular bodies by rashes and other symptoms. This finding suggests it is frequently assumed that mainstream practices are not harming our bodies, except when particularly reactive bodies express vulnerability. Depending on other experiences, this expression can be understood as exceptional rather than a symptom of something ongoing and ubiquitous. Moreover, Participant 1's reversion back to her old practices once the risk posed by chemicals in products was perceived to be less acute demonstrates the persistence of a notion of cleanliness centered on the elimination of microbes.

\section{Developing a New Research Agenda}

Ordinary domestic routines, and particularly cleaning practices, are contributing to unhealthy indoor home environments. To improve the environmental health of homes, the conceptualizations of hygiene embedded in current normative procedures 
must become more nuanced and encompassing of a broader range of hygiene risks beyond microbes. Practices that implicitly define "good" home hygiene and "cleaning well" as the extermination of dirt and germs require a significant amount of time, vigilance, and labor. This paper has highlighted that in the context of homes characterized by significant competition between practices for time, parents often feel they do not have the capacity to meet normative expectations of cleanliness. This combination of time pressure and high-demand cleaning practices results in the delegation of cleaning tasks to professionals and products that are perceived to clean fast and effectively. Most products, such as antibacterial wipes and surface sprays, generally contain a range of chemicals that help them smell fresh, create a "sparkly" surface, and sterilize with antibacterial agents. However, scientific research suggests that none of these product attributes are more effective than soap and water in creating a home environment free of potential pathogens (Aiello et al., 2007). They are creating a sense of cleanliness, while contributing significantly to the amount and diversity of chemicals in a home's microecology.

To investigate how cleaning practices could be reformed to address actual risks posed by microspecies in domestic spaces, it is proposed that the research approach presented herein is extended to develop a new transdisciplinary agenda. Based on the findings presented in this paper, a method for investigating indoor environmental health that continues to include, but does not prioritize, scientific understandings of the problem and potential solutions are evidently required. The dominant research discourses on indoor environmental health often presented in scientific journals frame such issues based on disciplinary orientation-notably particulate matter in indoor air (Meadow et al., 2014), chemicals in consumer products (Loretz et al., 2008), or the microbiology of built environments (Adams et al., 2016). A single discipline's exclusion of all variables within these indoor "ecosystems" and how they interact with one another leads to narrow definitions of the problem, and obfuscates solutions that do not fit disciplinary framings. Scientists examining the microbiome of built environments have begun to call for a new research program that accounts more for chemical use practices (National Academies of Sciences, Engineering, and Medicine, 2017). However, the integration of relevant scientific knowledge is only half the task. Unless social scientists, policy-makers, product manufacturers, and "users" are engaged to analyze how and why certain practices are leading to the development of particular microecologies, the designs of effective interventions will remain obscured. Finally, in addition to social and physical scientists, this paper has demonstrated the crucial role the design of both built environments and objects play in the reproduction of dominant domestic cleaning practices. Urban planners, architects, and designers will consequently contribute in any attempt to reorient material engagements to sensitize people to risk, and encourage practices that more accurately reflect the actual needs required for hygienic human habitation. 
For a transdisciplinary research agenda addressing suboptimal home environments to be effective and genuinely transdisciplinary, the boundaries that separate and stratify the disciplines and interest groups detailed in this paper must be transgressed. This will involve critical reflection on the politics of knowledge, which has prioritized scientific methods of knowing over "softer," more qualitative forms of inquiry or lay experiences in indoor environmental health research to date (Brown et al., 2010). As the body of research into social practices now attests (Blue, 2017; Hui et al., 2016; Shove et al., 2004), the outputs of this new research agenda must move beyond targeted messaging to individuals around behavior change. Rather, they must address the systemic, structural, material, bodily, and cognitive drivers of current practices at multiple scales, and across diverse populations. Such a research agenda has the potential to match knowledge about health risk with knowledge about the material culture, meanings, and habituated actions that constitute current home hygiene practices to gain a more sophisticated understanding of how this issue can be addressed, and by whom.

\section{References}

Adams, R. I., Bhangar, S., Dannemiller, K. C., Eisen, J. A., Fierer, N., Gilbert, J. A., ... Waring, M. S. (2016). Ten questions concerning the microbiomes of buildings. Building and Environment, 109, 224-234. doi.org/10.1016/j.buildenv.2016.09.001

Aiello, A. E., Larson, E. L., \& Levy, S. B. (2007). Consumer antibacterial soaps: Effective or just risky? Clinical Infectious Diseases, 45(Suppl 2), S137-S47. doi.org/10.1086/519255

Bergman, A., Heindel, J. J., Jobling, S., Kidd., K. A., \& Zoeller, R. T. (Eds.). (2013). State of the science of endocrine disrupting chemicals 2012. Geneva, Switzerland: World Health Organization/United Nations Environment Programme. Retrieved from www.who.int/ ceh/publications/endocrine/en/

Blue, S. (2017). Institutional rhythms: Combining practice theory and rhythmanalysis to conceptualise processes of institutionalisation. Time \& Society. doi. org/10.1177/0961463X17702165

Brown, V. A., Harris, J. A., \& Russell, J. Y. (2010). Tackling wicked problems through the transdisciplinary imagination. London, UK, Washington, DC: Earthscan.

Campkin, B., \& Cox, R. (Eds.). (2012). Dirt: New geographies of cleanliness and contamination. London, UK, New York, NY: I. B. Tauris.

Clayton, E. M. R., Todd, M., Dowd, J. B., \& Aiello, A. E. (2011). The impact of bisphenol A and triclosan on immune parameters in the U.S. population, NHANES 2003-2006. Environmental Health Perspectives, 119(3), 390-396. doi.org/10.1289/ehp.1002883

Creswell, J. W. (1998). Quality inquiry and research design: Choosing among five traditions. Thousand Oaks, CA: Sage. 
Dunn, R. R., Fierer, N., Henley, J. B., Leff, J. W., \& Menninger, H. L. (2013). Home life: Factors structuring the bacterial diversity found within and between homes. PloS One, 8(5), e64133. doi.org/10.1371/journal.pone.0064133

Dyball, R., \& Newell, B. (2014). Understanding human ecology: A systems approach to sustainability. London, UK: Routledge.

Flores, G. E., Bates, S. T., Caporaso, J. G., Lauber, C. L., Leff, J. W., Knight, R., \& Fierer, N. (2013). Diversity, distribution and sources of bacteria in residential kitchens. Environmental Microbiology, 15(2), 588-596. doi.org/10.1111/1462-2920.12036

Forouzanfar, M. H., Alexander, L., Anderson, H. R., Bachman, V. F., Biryukov, S., Brauer, M., ... Murray, C. J. (2015). Global, regional, and national comparative risk assessment of 79 behavioural, environmental and occupational, and metabolic risks or clusters of risks in 188 countries, 1990-2013: A systematic analysis for the Global Burden of Disease Study 2013. The Lancet, 386(10010), 2287-2323. doi.org/10.1016/S01406736(15)00128-2

Gosens, I., Delmaar, C. J. E., ter Burg, W., de Heer, C., \& Schuur, A. G. (2014). Aggregate exposure approaches for parabens in personal care products: A case assessment for children between 0 and 3 years old. Journal of Exposure Science and Environmental Epidemiology, 24(2), 208-214. doi.org/10.1038/jes.2013.33

Greaves, M. (2018). A causal mechanism for childhood acute lymphoblastic leukaemia. Nature Reviews Cancer, 18(8), 471-484. doi.org/10.1038/s41568-018-0015-6

Halden, R. U., Lindeman, A. E., Aiello, A. E., Andrews, D., Arnold, W. A., Fair, P., ... Blum, A. (2017). The florence statement on triclosan and triclocarban. Environmental Health Perspectives, 125(6), 064501. doi.org/10.1289/EHP1788

Hui, A., Schatzki, T., \& Shove, E. (Eds.). (2016). The nexus of practices: Connections, constellations, practitioners. London, UK: Routledge.

Koo, H. (2016). The global middle class: How is it made, what does it represent? Globalizations, 13(4), 440-453. doi.org/10.1080/14747731.2016.1143617

Kumar, P., Skouloudis, A. N., Bell, M., Viana, M., Carotta, M. C., Biskos, G., \& Morawska, L. (2016). Real-time sensors for indoor air monitoring and challenges ahead in deploying them to urban buildings. Science of the Total Environment, 560-561, 150-159. doi.org/ 10.1016/j.scitotenv.2016.04.032

Loretz, L. J., Api, A. M., Babcock, L., Barraj, L. M, Burdick, J., Cater, K. C, ... Scrafford, C. G. (2008). Exposure data for cosmetic products: Facial cleanser, hair conditioner, and eye shadow. Food and Chemical Toxicology, 46(5), 1516-1524. doi.org/10.1016/ j.fct.2007.12.011

Lupton, E., \& Miller, J. A. (1996). Bathroom, the kitchen, and the aesthetics of waste. Dalton: Princeton Architectural Press.

Lyytimäki, J. (2012). Indoor ecosystem services: Bringing ecology and people together. Human Ecology Review, 19(1), 70-76. Retrieved from www.jstor.org/stable/24707616 
Mackendrick, N. (2014). More work for mother: Chemical body burdens as a maternal responsibility. Gender \& Society, 28(5), 705-728. doi.org/10.1177/0891243214529842

Maller, C. (2018). Healthy urban environments: More-than-human theories. Abingdon, UK: Routledge.

Malterud, K., Siersma, V. D., \& Guassora, A. D. (2016). Sample size in qualitative interview studies: Guided by information power. Qualitative Health Research, 26(13), 1753-1760. doi.org/10.1177/1049732315617444

Martin, L. J., Adams, R. I., Bateman, A., Bik, H. M., Hawks, J., Hird, S. M., ... Dunn, R. R. (2015). Evolution of the indoor biome. Trends in Ecology \& Evolution, 30(4), 223-232. doi.org/10.1016/j.tree.2015.02.001

Meadow, J. F., Altrichter, A. E., Kembel, S. W., Kline, J., Mhuireach, G., Moriyama, M., ... Bohannan, B. J. (2014). Indoor airborne bacterial communities are influenced by ventilation, occupancy, and outdoor air source. Indoor Air, 24(1), 41-48. doi.org/ 10.1111/ina. 12047

Morse, J. M. (1994). Designing funded qualitative research. In N. K. Denzin \& Y. S. Lincoln (Eds.), Handbook of qualitative research (pp. 220-235). Thousand Oaks, CA: Sage.

Murphy, M. (2006). Sick building syndrome and the problem of uncertainty: Environmental politics, technoscience, and women workers. Durham, NC: Duke University Press.

National Academies of Sciences, Engineering, and Medicine. (2017). Microbiomes of the built environment: A research agenda for indoor microbiology, human health, and buildings. Washington, DC: National Academies Press. doi.org/10.17226/23647

National Toxicology Program. (2018). About NTP. Retrieved May 31, 2018, from ntp. niehs.nih.gov/about/

Oxford English Dictionary (2016). Hygiene. In Oxford English Dictionary. Retrieved from www.oxforddictionaries.com/definition/english/hygiene

Pink, S., \& Mackley, K. L. (2015). Social science, design and everyday life: Refiguring showering through anthropological ethnography. Journal of Design Research, 13(3), 278-292. doi.org/10.1504/JDR.2015.071454

Reckwitz, A. (2002). Toward a theory of social practices: A development in culturalist theorizing. European Journal of Social Theory, 5(2), 243-263. doi.org/10.1177/136843 1002005002005

Rintala, H., Pitkäranta, M., Toivola, M., Paulin, L., \& Nevalainen, A. (2008). Diversity and seasonal dynamics of bacterial community in indoor environment. BMC Microbiology, 8(1), 56. doi.org/10.1186/1471-2180-8-56

Rook, G. A. W., Lowry, C. A., \& Raison, C. L. (2013). Microbial "old friends", immunoregulation and stress resilience. Evolution, Medicine, and Public Health, 2013(1), 46-64. doi.org/10.1093/emph/eot004 
Schoot Uiterkamp, A. J. M, \& Vlek, C. (2007). Practice and outcomes of multidisciplinary research for environmental sustainability.Journalof Social Issues, 63(1), 175-197. Retrieved from www.rug.nl/research/portal/files/10244576/2007JSocIssSchootUiterkamp.pdf

Schor, J. (1998). Beyond work and spend: Time, leisure and consumption. In S. Scraton (Ed.), Leisure, time and space: Meanings and values in people's lives (LSA publication no. 57, pp. 7-12).

Sherriff, A., Farrow, A., Golding, J., \& Henderson, J. (2005). Frequent use of chemical household products is associated with persistent wheezing in pre-school age children. Thorax, 60(1), 45-49. doi.org/10.1136/thx.2004.021154

Shove, E. (2003). Comfort, cleanliness and convenience: The social organization of normality (vol. 810). Oxford, UK: Berg.

Shove, E. (2004). Comfort, cleanliness and convenience: The social organization of normality (New technologies/new cultures, 1st ed.). Oxford, UK, Berg.

Shove, E., Pantzar, M., \& Watson, M. (2012). The dynamics of social practice: Everyday life and how it changes. London, UK: Sage.

Smith, V. (2007). Clean: A history of personal hygiene and purity. Oxford, UK: Oxford University Press.

Sofoulis, Z. (2005). Big water, everyday water: A sociotechnical perspective. Continuum, 19(4), 445-463. doi.org/10.1080/10304310500322685

Southerton, D. (2006). Analysing the temporal organization of daily life: Social constraints, practices and their allocation. Sociology, 40(3), 435-454. doi.org/10.1177/ 0038038506063668

Wakefield-Rann, R. (2017). More than skin deep: A service design approach to making the luxury personal care industry more sustainable. In M. Gardetti (Ed.), Sustainable management of luxury (pp. 211-231). Singapore: Springer. doi.org/10.1007/978-98110-2917-2_10

Wakefield-Rann, R., Fam, D., \& Stewart, S. (2018). Routine exposure: Social practices and environmental health risks in the home, Social Theory and Health, 1-18. doi.org/ 10.1057/s41285-018-00084-8

Weschler, C. J. (2009). Changes in indoor pollutants since the 1950s. Atmospheric Environment, 43(1), 153-169. doi.org/10.1016/j.atmosenv.2008.09.044

Wickson, F., Carew, A. L., \& Russell, A. W. (2006). Transdisciplinary research: Characteristics, quandaries and quality. Futures, 38(9), 1046-1059. doi.org/10.1016/ j.futures.2006.02.011

Zoeller, R. T., Brown, T. R., Doan, L. L., Gore, A. C., Skakkebaek, N. E., Soto, A. M., ... Vom Saal, F. S. (2012). Endocrine-disrupting chemicals and public health protection: A statement of principles from The Endocrine Society. Endocrinology, 153(9), 4097-4110. doi.org/10.1210/en.2012-1422 
This text is taken from Human Ecology Review, Volume 24, Number 2, 2018, published by ANU Press, The Australian National University, Canberra, Australia. doi.org/10.22459/HER.24.02.2018.04 